\title{
COLONIZAÇÃO DE ESTROMAS DE Sphaerodothis acrocomiae AGENTE CAUSAL DA LIXA GRANDE DO COQUEIRO POR Acremonium persicinum
}

\author{
DULCE REGINA NUNES WARWICK
}

Embrapa Tabuleiros Costeiros. Cx. Postal 44, CEP 49001-970. Aracaju, SE, e-mail: dulce@cpatc.embrapa.br

\section{ABSTRACT \\ Stromata colonization of Sphaerodothis acrocomiae causal agent of the coconut large verrucosis by Acremonium persicinum}

The factors affecting the biological control of large verrucosis (Sphaerodothis acrocomiae) of coconuts (Cocos nucifera) with the utilization of the hiperparasite fungus Acremonium persicinum were studied. This hiperparasite is found mainly in the rainy season (April-august) colonizing stromata of large verrucosis as well as small verrucosis. On culture the fungus produces a fine mycelium, with single, small, hyaline conidium and on PDA the culture has a purplish color. The $10^{7}$ conidia per $\mathrm{ml}$ were the smaller concentration, which gave a bigger colonization in the field trial. The application of the hiperparasite gives best results in the rainy season and when performed i1n the afternoon.
As lixas do coqueiro (Cocos nucifera L.) são colonizadas naturalmente por fungos hiperparasitas. $\mathrm{Na}$ tentativa de viabilizar o controle das mesmas através da aplicação controlada de agentes reproduzidos em laboratório, avaliaram-se diferentes formas de utilização de Acremonium persicinum (Nicot.) W. Gams, em nível de campo.

Em um plantio comercial de coqueiro híbrido (anão vermelho do brasil $\mathrm{x}$ gigante do brasil), com dois anos de implantação e naturalmente atacado pela lixa grande, foram avaliados os parâmetros preliminares para a utilização do controle biológico no campo. Inicialmente foram utilizados pulverizações com $1 \times 10^{5}, 1 \times 10^{6}, 1 \times 10^{7}$ conídios por ml. às $9 \mathrm{~h}$ da manhã e vespertina (após as 16 h). Foram feitas aplicações quinzenais durante todo o ano de 1997. A avaliação contou da coleta de 12 folíolos das três últimas folhas para a contagem de estromas parasitados e não parasitados, 15 dias após a aplicação do hiperparasita.

A aplicação matinal de $A$. persicinum no campo não teve resultado satisfatório, também a aplicação em meses secos, não resultou em uma colonização efetiva dos estromas pelo hiperparasita (Tabela 1). Verificou-se ainda que a concentração de $10^{7}$ conídios por ml foi a que proporcionou o melhor resultado durante o experimento realizado (Tabela 1 ).

O sucesso do biocontrole de patógenos da parte aérea das plantas é parcial e limitado quando comparados com o biocontrole de patógenos causadores de doenças do sistema radicular. A baixa eficiência do controle biológico dos patógenos foliares depende ainda de um bom agente veiculante e do impacto do meio ambiente.

TABELA 1 - Percentagem média de estromas colonizados de lixa grande, em folíolos coqueiro (Cocos nucifera), duas semanas após a aplicação do fungo hiperparasita Acremonium persicinum

\begin{tabular}{lccc}
\hline \hline $\begin{array}{l}\text { Tipo de aplicação do } \\
\text { hiperparasita }\end{array}$ & $\begin{array}{c}\text { Estromas colonizados } \\
(\mathbf{\%}) \mathbf{. 1 0}\end{array}$ & $\begin{array}{c}\text { Estromas colonizados } \\
(\mathbf{\%}) \mathbf{. 1 0}\end{array}$ & $\begin{array}{c}\text { Estromas colonizados } \\
\mathbf{( \% )} . \mathbf{. 1 0}^{\mathbf{7}}\end{array}$ \\
\hline Período seco, matinal & $4 \%$ & $12 \%$ & $17 \%$ \\
Período seco, vespertino & $13 \%$ & $15 \%$ & $20 \%$ \\
Período chuvoso, matinal & $15 \%$ & $16 \%$ & $19 \%$ \\
Período. chuvoso, vespertino & $28 \%$ & $45 \%$ & $68 \%$ \\
\hline
\end{tabular}

